\title{
Baseline Predictors of Renal Disease Progression in the African American Study of Hypertension and Kidney Disease
}

\author{
Keith C. Norris ${ }^{\star}$, Tom Greene ${ }^{\dagger}$, Joel Kopple ${ }^{\ddagger}$, Janice Lea§, Julia Lewis\|l, Mike Lipkowitzף, \\ Pete Miller $^{\star *}$, Annie Richardson ${ }^{\dagger \dagger}$, Stephen Rostand ${ }^{\ddagger \ddagger}$, Xuelei Wang ${ }^{\dagger}$, Lawrence J. Appel ${ }^{\star \star}$, \\ and for the AASK Study Group
}

"Charles R. Drew University, Los Angeles, California ${ }^{\dagger}$ Cleveland Clinic Foundation, Cleveland, Ohio ¥ Harbor-UCLA Medical Center, Torrance, California §Emory University, Atlanta, Georgia \|Vanderbilt University, Nashville, Tennessee IMount Sinai School of Medicine, New York, New York ${ }^{* *}$ Johns Hopkins University, Baltimore, Maryland †tUniversity of Southern California, Los Angeles, California 执University of Alabama, Birmingham, Alabama

\begin{abstract}
Patients with chronic kidney disease have an increased risk for progression to ESRD. The purpose of this study was to examine factors that predict increased risk for adverse renal outcomes. Cox regression was performed to assess the potential of 38 baseline risk factors to predict the clinical renal composite outcome of $50 \%$ or $25-\mathrm{ml} / \mathrm{min}$ per $1.73 \mathrm{~m}^{2}$ GFR decline or ESRD among 1094 black patients with hypertensive nephrosclerosis (GFR 20 to $65 \mathrm{ml} / \mathrm{min}$ per $1.73 \mathrm{~m}^{2}$ ). Patients were trial participants who had been randomly assigned to one of two BP goals and to one of three antihypertensive regimens and followed for a range of 3 to $6.4 \mathrm{yr}$. In unadjusted and adjusted analyses, baseline proteinuria was consistently associated with an increased risk for adverse renal outcomes, even at low levels of proteinuria. The relationship of proteinuria with adverse renal outcomes also was evident in analyses that were stratified by level of GFR, which itself was associated with adverse renal outcomes but only at levels $<40 \mathrm{ml} / \mathrm{min}$. Other factors that were significantly associated with increased renal events after adjustment for baseline GFR, age, and gender, both with and without adjustment for baseline proteinuria, included serum creatinine, urea nitrogen, and phosphorus. In black patients with hypertensive nephrosclerosis, increased proteinuria, reduced GFR, and elevated levels of serum creatinine, urea nitrogen and phosphorus were directly associated with adverse clinical renal events. These findings identify a subset of this high-risk population that might benefit from even more aggressive treatment.
\end{abstract}

Patients with chronic kidney disease (CKD) are at increased risk for progression to ESRD and for premature cardiovascular disease (CVD) (1-4). The number of individuals who receive renal replacement therapy for ESRD continues to increase and now has reached epidemic proportions (5). Whereas the estimated prevalence of CKD is similar for black and white individuals (6), the adjusted incidence of ESRD among black individuals is the highest among racial/ ethnic subgroups of the US population and at 988 per million is nearly four times more common than their white counterparts at 254 per million (3). The magnitude of hypertension-related ESRD among black individuals is highlighted by a nearly six-fold higher incidence than in white individuals; among 20- to 44-yr-olds, the incidence of hypertension-related ESRD in black individuals is $>15$ times that of white individuals (3).

Copyright $(92006$ by the American Society of Nephrology

Address correspondence to: Dr. Keith Norris, Associate Dean for Research, Charles R. Drew University, 1731 E. 120th Street, Los Angeles, CA 90059. Phone: 323-249-5702; Fax: 323-357-0747; knorris@ucla.edu. 
Indeed, black race, male gender, hypertension, and hypercreatinemia have been noted as powerful predictors of development of hypertension-related ESRD (7). The level of proteinuria also has been found to be an especially strong predictor of the rate of progression in a wide range of CKD populations, including black individuals with hypertensive nephrosclerosis (8). Additional factors that contribute to the more rapid progression from CKD to ESRD among black individuals have not been defined clearly, although higher prevalence of traditional CKD risk factors, worse clinical control of comorbid conditions, socioeconomic factors, and limited access to care may play a role (9-12).

Until recently, no prospective trials were designed to reduce the risk for development of ESRD among black individuals with hypertension-related CKD. Results from the African American Study of Hypertension and Kidney Disease (AASK) revealed a significant benefit of initial antihypertensive therapy with an angiotensin-converting enzyme inhibitor, ramipril, in comparison with a dihydropyridine calcium channel blocker, amlodipine, or a $\beta$ blocker, metoprolol, for reducing clinical composite outcome $(50 \%$ or $25-\mathrm{ml} / \mathrm{min}$ per 1.73 $\mathrm{m}^{2}$ decline in GFR, ESRD, or death) $(13,14)$. The extensive baseline data that were collected in the AASK provide a unique opportunity to identify factors that predict adverse renal outcomes in this understudied high-risk population.

In this setting, we performed a systematic investigation of the relationships between baseline risk factors and subsequent renal events. Because initial proteinuria has been reported consistently to be the single strongest risk factor for subsequent disease progression in CKD cohorts, we also addressed the question of whether relationships that are observed between other potential risk factors and renal events can be accounted for by associations between those risk factors and proteinuria and examined the extent to which these relationships persist after taking into account the level of baseline proteinuria. These analyses should provide useful information that can inform prevention and early treatment strategies that are designed to prevent the progression of CKD.

\section{Materials and Methods}

\section{Participants and Study Design}

The study design was described previously (13-15). Briefly, participants were randomly assigned to a usual mean arterial pressure (MAP) goal of 102 to $107 \mathrm{mmHg}$ or to a lower MAP goal of $<92 \mathrm{mmHg}$ and to treatment with one of three antihypertensive drugs (metoprolol, ramipril, or amlodipine). Participants were self-identified black individuals with hypertension $(n=1094)$, were aged 18 to $70 \mathrm{yr}$, had GFR between 20 and $65 \mathrm{ml} / \mathrm{min}$ per $1.73 \mathrm{~m}^{2}$, and had no other identified causes of renal insufficiency. Exclusion criteria were (I) diastolic BP $<95 \mathrm{mmHg}$, (2) known history of diabetes (fasting glucose $>140 \mathrm{mg} / \mathrm{dl}$ or random glucose $>200 \mathrm{mg} / \mathrm{dl}$ ), (3) urinary protein-to-creatinine ratio (UP/Cr) $>2.5$, (4) accelerated or malignant hypertension within $6 \mathrm{mo},(5)$ secondary hypertension, (6) evidence of non-BP-related causes of renal disease, ( 7 ) serious systemic disease, ( 8 ) clinical congestive heart failure, or (9) specific indication for or contraindication to a study drug or study procedure. The institutional review board at each center approved the protocol and procedures. An independent data, safety, and monitoring board also approved and monitored the study. All participants gave written informed consent. Participant enrollment began in February 1995 and ended in September 1998. Follow-up to the end of the study ranged from 3 to $6.4 \mathrm{yr}$.

\section{Measurement of Baseline and Follow-Up Demographic, Laboratory, and Clinical Data}

Baseline information was collected for family history, review of systems, lifestyle habits, education, and family income. A central laboratory measured baseline serum and urinary 
chemistry levels, and GFR was assessed by 125 -iothalamate clearance. Urinary protein excretion was expressed as the UP/Cr from a 24-h urine collection. Three consecutive seated BP were measured using a Hawksley random zero sphygmomanometer after at least 5 min of rest, with the mean of the last two readings recorded $(13,16)$. The baseline BP were those that were obtained at the screening visits before randomization. Throughout this report, GFR is expressed after standardization for body surface area in units of $\mathrm{ml} / \mathrm{min}$ per $1.73 \mathrm{~m}^{2}$. Baseline electrocardiograms (ECG) were obtained and read locally (14). Abnormal ECG findings were defined in response to the following question: Is the ECG completely normal, yes or no? Left ventricular hypertrophy $(\mathrm{LVH})$ was defined by voltage criteria, V1+V5 or $\mathrm{V} 6>35 \mathrm{~mm}$, or V5 or V6>25 mm.

\section{Outcome Variables}

The main outcome variable in this report is a clinical renal composite given by the time from randomization to either $(I)$ a GFR event, defined by a confirmed decline in GFR by either $50 \%$ or $25 \mathrm{ml} / \mathrm{min}$ per $1.73 \mathrm{~m}^{2}$ from the mean of two baseline GFR measurements, or (2) occurrence of ESRD. Because censoring of patients who died before reaching ESRD may bias relationships of the renal composite outcome with baseline factors, we conducted parallel analyses using an extended clinical composite outcome defined by the occurrence of either death or the renal end points listed in (I) or (2).

\section{Statistical Analyses}

Before the statistical analyses, the investigators selected the 38 factors that are listed in Table 1 as potential risk factors for investigation. The factors were selected to incorporate a wide range of domains, including initial renal function, BP and CVD, traditional risk factors for CVD, biochemical markers of nutritional status, socioeconomic status, and other biochemistry and behavior factors that have been hypothesized to be associated with renal disease progression. Cox regression analyses were used to relate the two composite outcomes individually with four of these factors: Age, gender, baseline GFR, and baseline proteinuria. Further Cox regressions then were used to relate the composite outcomes individually to each of the remaining 34 baseline factors using two different levels of covariate adjustment: First controlling for baseline GFR, age, and gender and second controlling for proteinuria (expressed as the $\log \mathrm{UP} / \mathrm{Cr}$ ) in addition to the first three factors. Subsequently, interaction terms with the randomized treatment groups were added to the Cox models to determine whether the treatment assignments modified the associations of the composite outcomes with the baseline factors. The adjustment for baseline GFR reflects our objective to evaluate the association of the baseline factors with subsequent progression of disease rather than the initial level of GFR. Age and gender also were included as covariates because they are nonmodifiable risk factors and because the interpretation of relationships that involve other factors was believed to be clearer after controlling for these basic demographic characteristics. Separate analyses were performed with and without adjustment for proteinuria to assess whether relationships between specific factors and the composite outcomes persist independent of the level of proteinuria.

Analyses of the renal composite, including GFR events and ESRD, were censored at death, permanent loss to follow-up before the end of the trial (nine patients), or the end of the study (September 2001 for patients in the ramipril and metoprolol groups and $1 \mathrm{yr}$ earlier for patients in the amlodipine group, which was discontinued before the end of the trial on the recommendation of the Data Safety and Monitoring Board [14]). Analyses of the extended clinical composite including death were censored at permanent loss to follow-up or the end of the study. Because of the presence of nonlinear relationships, segmented linear spline terms were used to provide separate estimates of the hazard ratios (HR) of baseline GFR and serum urea nitrogen below and above their median values. Finally, in addition to the 
designated baseline factors, each of the Cox regression models controlled for the randomized treatment assignments, and analyses that adjusted for baseline proteinuria also included interaction terms between $\log \mathrm{UP} / \mathrm{Cr}$ and the treatment assignments.

The assumption of proportional hazards in the Cox regression models was checked by consideration of linear interactions between the 38 baseline factors and follow-up time. The $P$ values for the interaction tests exceeded 0.05 (indicating no violation of proportional hazards) for all factors except years with hypertension $(P=0.03)$ and serum urea nitrogen $(P$ $=0.04)$. These two marginally significant $P$ values provide only weak evidence for nonproportional hazards given the large number of interactions considered, and estimation of separate HR for the first $2 \mathrm{yr}$ versus later in follow-up did not reveal clinically important differences. Hence, overall HR are presented, assuming proportional hazards throughout the follow-up period. Unless indicated otherwise, two-sided $P<0.05$ is designated as statistically significant, without adjustment for multiple comparisons.

\section{Results}

\section{Baseline Clinical Characteristics}

The mean age of the participants was $54.6 \pm 10.7 \mathrm{yr}$, and $670(61 \%)$ were male. Average prestudy duration of hypertension was $14.2 \pm 10.1 \mathrm{yr}$. The average number of antihypertensive medications classes was $2.5 \pm 1.1$ per participant. The mean body mass index was $30.6 \pm 6.6 \mathrm{~kg} / \mathrm{m}^{2}$, and baseline systolic and diastolic BP were $150 \pm 24$ and $96 \pm$ $14 \mathrm{mmHg}$, respectively. The serum creatinine level was $2.0 \pm 0.7 \mathrm{mg} / \mathrm{dl}$ with a mean GFR of $46 \pm 14 \mathrm{ml} / \mathrm{min}$ per $1.73 \mathrm{~m}^{2}$. Characteristics that included mean values and/or frequencies for the 38 potential baseline risk factors are shown for the entire cohort as well as stratified by the level of baseline proteinuria and GFR (Table 1). Baseline proteinuria is stratified at an UP/Cr of 0.22 , which corresponds approximately to a $24-\mathrm{h}$ protein excretion of $300 \mathrm{mg} / \mathrm{d}$ and divides the two thirds with the lowest proteinuria from the one third with the highest proteinuria, in accordance with the positive skewness of this variable (15).

\section{Analysis of Risk Predictors for the Renal Composite Outcome (Time to GFR Event or ESRD)}

The mean duration of follow-up until GFR event, ESRD, death, or censoring at the end of the study was $3.9 \mathrm{yr}$ (median $4.0 \mathrm{yr}$ ). As shown in Table 2, in univariate analyses, the renal composite outcome was strongly associated with higher baseline urinary protein excretion throughout the full range of proteinuria values (HR 1.59 per two-fold increase; $95 \%$ confidence interval $[\mathrm{CI}] 1.50$ to $1.69 ; P<0.001)$. The renal composite was inversely associated with baseline GFR at lower levels of GFR (HR 1.71 per $5-\mathrm{ml} / \mathrm{min}$ per $1.73 \mathrm{~m}^{2}$ decrease in GFR when GFR was $\$ 40 \mathrm{ml} / \mathrm{min}$ per $1.73 \mathrm{~m}^{2} ; 95 \%$ CI 1.53 to $1.90 ; P<0.001$ ). For GFR for values $>40 \mathrm{ml} / \mathrm{min}$, there was a similar trend that did not reach statistical difference (HR 1.07; 95\% CI 0.97 to $1.17 ; P=0.16$ ). Each $10 \mathrm{yr}$ of age was associated with a $26 \%$ reduced risk for adverse renal event (HR $0.74 ; 95 \%$ CI 0.67 to $0.83 ; P<0.001$ ), whereas no significant relationship was observed for gender.

Because the baseline UP/Cr and GFR were strongly predictive of the renal composite outcome, their joint relationship is shown in Figure 1. Figure 1 shows that the strong overall association of the renal composite with baseline proteinuria persisted after controlling for the level of baseline GFR. At each stratum of GFR, as the UP/Cr ratio increased, so did the risk for the composite renal outcome. The association between the proteinuria category and the log hazard ratio for the renal composite tended to be stronger in the lower GFR strata (interaction $P=0.04$ ). Conversely, in strata that were defined by baseline $\mathrm{UP} / \mathrm{Cr}$, as baseline 
GFR decreased, the risk for the composite renal outcome tended to increase, although the relationship was less consistent in the lowest stratum of UP/Cr ( $₫ 0.08)$.

Table 3 describes the association of the remaining 34 baseline factors with the renal composite while controlling for randomized group, baseline GFR, age, and gender, both with and without adjustment for baseline proteinuria. A total of 15 factors, listed first in Table 3, reached statistical significance with an unadjusted $P<0.05$ for one or both of these analyses. Factors that were significantly associated with an increased risk for the renal composite after adjustment for baseline GFR, age, and gender, both with and without adjustment for baseline proteinuria, included higher serum creatinine, urine urea nitrogen, and serum phosphorus. Paradoxically, a self-reported history of heart disease, evidence of LVH on ECG, or an abnormal ECG were each associated with a reduced risk for the renal composite outcome. Six additional baseline factors were significantly associated with the renal composite without adjustment but not with adjustment for baseline proteinuria. These included greater body weight, higher serum glucose, higher triglyceride concentration, lower serum albumin, and higher levels of both urine urea nitrogen when $>7.8$ and urine sodium. In most cases, the HR of these six factors attenuated substantially toward 1.00 after adjustment for proteinuria. Finally, the risk that was associated with three factorshematocrit, MAP, and systolic BP—became statistically significant only after adjustment for proteinuria.

Figure 2 presents the HR of the renal composite outcomes, with and without death, for the 16 factors with $P<0.05$ for at least one of the analyses in Table 3 plus current smoking, which was positively associated with the renal composite outcome that included death. The hazard ratios are expressed per 1-SD increase in the respective baseline factors, so the sizes of the effects can be compared between factors that are measured in different units. Baseline proteinuria was the strongest predictor of progression for both of the composite outcomes among the factors considered. The paradoxic trends that suggested a reduced rate of renal events among patients with cardiovascular risk factors attenuated and no longer reached statistical significance when death was included in the composite outcome, although the direction of the relationships remained unchanged.

\section{Interactions with Treatment Group}

When considered without adjustment for other baseline factors, the association of baseline proteinuria with the renal composite outcome was slightly stronger for patients who were assigned to the usual BP group than the low BP group (HR 1.72 per two-fold increase in UP/ $\mathrm{Cr}$ in the usual $\mathrm{BP}$ group versus 1.41 per two-fold increase in the low $\mathrm{BP}$ group; $P=0.001$ for interaction). Relationships between the renal composite outcome and drug groups and several other baseline factors also exhibited nominally significant differences between the treatment groups $(P<0.05)$, but no consistent pattern that would alter the conclusions of this article emerged (data not shown).

\section{Discussion}

This systematic investigation of the baseline variables that were collected in the AASK identified several factors that were predictive of subsequent renal outcomes among black individuals with hypertensive nephrosclerosis. In particular, higher levels of urine protein excretion, elevated serum creatinine, and a lower initial GFR were highly predictive of an increased risk for the composite clinical renal outcome. Importantly, the relationship between proteinuria and renal outcomes was evident in each stratum of baseline GFR. Of note, the strong, graded association between proteinuria and renal outcomes was noted even at very low levels of proteinuria. Previous reports of this association have been in patient populations with higher levels of proteinuria. 
The finding of a strong direct association of urinary protein excretion with clinical renal outcomes in our study confirms and expands on previous findings from randomized prospective CKD trials $(17,18)$. We also found that the association between rate of renal events and baseline GFR was greater at values below compared with those above $40 \mathrm{ml} / \mathrm{min}$ (as did GFR slope; data not shown), suggesting a nonlinear relationship between hypertensive CKD and decline in renal function. This is in contrast to the Modification of Diet in Renal Disease (MDRD) trial, which reported a linear mean GFR decline as renal disease progressed (19). These contrasting results support heterogeneity in the progression of CKD and/or potential response to therapy by etiology and population examined.

Heterogeneity within hypertensive nephrosclerosis was described by Bohle et al. (20), who identified and characterized three distinct histologic classes: (1) compensated benign, (2) decompensated benign, and (3) malignant. The clinical profile of these histologic classes also differs, with the more severe forms of hypertensive nephrosclerosis occurring at an earlier age. This may help explain, in part, the inverse relationship between age and rate of adverse renal outcomes. Alternatively, for any given level of baseline GFR, increased age may serve as a surrogate for a slower rate of disease progression; as for the older patients, renal disease may have progressed over a longer period to reach the same GFR.

Although CKD generally is associated with an increase in CVD events, in the AASK cohort, baseline LVH, abnormal ECG, and history of heart disease each were unexpectedly associated with a reduced risk for clinical renal outcomes. By contrast, previous crosssectional studies had reported that the presence of CVD predicted a faster decline of kidney function and earlier need for dialysis (21), and several studies have noted a direct association between increased prevalence of LVH and advanced stages of CKD $(22,23)$. One potential explanation for this pattern is the occurrence of informative censoring of renal outcomes from the competing risk for death. That is, patients with cardiovascular risk factors may have been more likely to die before the occurrence of renal events, thus distorting the relationship between cardiovascular risk factors and clinical renal outcomes when follow-up time is censored at death. The possibility of informative censoring is suggested by the analyses of the composite renal outcome including death, in which apparent protective effects of the noted cardiovascular risk factors were diminished and no longer statistically significant.

Alternative explanations for our findings include an early expression of reverse epidemiology for CVD that more commonly is seen in patients with ESRD (24) and selection bias (individuals with severe CVD were excluded or did not enroll in the trial). It also is possible that the lower risk for renal events in the patients with higher baseline BP and other cardiovascular risk factors is related to the large reduction in BP levels that was experienced by the large majority of AASK participants, irrespective of their randomized treatment group assignment (25). Because the reduction in BP during the trial was larger in patients with higher initial BP, it is possible that higher BP levels and associated cardiovascular risk factors at entry identified patients who benefited the most from their participation in the trial, thus reducing their risk for adverse events. Finally, because several analyses were considered for each of a large number of risk factors, it is not unlikely that some associations with $P<0.05$ are spurious positive results from multiple analyses.

It is interesting that cigarette smokers compared with non-smokers did not predict clinical renal outcomes, in contrast to two cross-sectional studies that linked smoking to CKD progression $(26,27)$. A prospective evaluation of 84 patients who had type 2 diabetes and underwent BP control with angiotensin-converting enzyme inhibition noted that both cigarette smoking and increased proteinuria were interrelated predictors of nephropathy progression (28). Similarly, a multivariate analysis of 53 patients who had essential hypertension and were followed prospectively for 36 mo found that cigarette smoking, the 
baseline creatinine level, and black ethnicity were the only variables that were associated with faster progression of kidney disease (29). However, we did note a strong association between smoking and the renal composite outcome when death was included; this finding suggests the possibility of informative censoring.

Anemia is more likely to occur as GFR declines (30). A lower baseline serum hematocrit was found to be an independent risk for adverse renal events after adjustment for age, gender, and both baseline GFR and proteinuria $(P=0.01)$, consistent with previous observations (19), as well as analyses of clinical predictors for morbidity and mortality at initiation of dialysis (31-34). Although the precise mechanism(s) whereby anemia might influence progression of kidney disease remains unclear, altered oxygen delivery to the kidney and the heart has been posited as an important contributor $(34,35)$.

Although the association of increased serum creatinine and increased renal and other vascular outcomes is well established (1-4,36,37), the finding of elevated baseline creatinine level to predict independently an increase in renal outcome events even after controlling for GFR was somewhat unexpected but may be related to the BP goal intervention. In the MDRD study, serum creatinine concentration was noted to vary independent of GFR as a result of differences in dietary protein intake (affecting creatinine secretion and excretion) and lower BP goal (affecting creatinine secretion) but not class of antihypertensive agents (38). The association of increased serum phosphorus levels with both clinical renal events and the composite of clinical renal events and death builds on similar recent findings in both ESRD and CKD populations $(39,40)$.

\section{Conclusion}

Our findings reinforce the observations that proteinuria and baseline GFR are powerful predictors of CKD progression for this high-risk hypertensive nephropathy population (black individuals) that was followed closely for approximately $4 \mathrm{yr}$. Although proteinuria and estimated GFR are not measured routinely in many clinical settings, they are relatively simple clinical studies to obtain. The finding of significant predictive value for clinical renal events with serum creatinine, hematocrit, and urea nitrogen provide further support for these markers both in creating an overall risk profile and for designing future prospective evaluations of highly specific interventions.

\section{Acknowledgments}

In addition to funding under a cooperative agreement from National Institute of Diabetes and Digestive and Kidney Diseases, this study was supported in part by the following institutional General Clinical Research Centers and other National Institutes of Health grants: M01 RR-00080, 5M01 RR-00071, M01 00032, P20-RR11145, M01 RR00827, M01 RR00052, 2P20 RR11104, and DK 2818-02.

These data were presented in part at the annual meeting of the American Society of Nephrology, November 12 through 17, 2003, in San Diego, CA.

The AASK Study Group includes the following. Case Western Reserve University: J. Wright (Principal Investigator), Y. Hall (Study Coordinator), R. Haynie, C. Mbanefo, M. Rahman, M. Smith, B. Crenshaw, R. Dancie, L. Jaen; Emory University: J. Lea (Principal Investigator), A. Chapman, L. Dean, M. Douglas (Study Coordinator), D. Watkins, B. Wilkening, L. Williams, C. Ross; Harbor-UCLA Medical Center: J. Kopple (Principal Investigator), L. Miladinovich (Study Coordinator), P. Oleskie; Harlem Hospital Center: V. Pogue (Principal Investigator), D. Dowie (Study Coordinator), H. Anderson, L. Herbert, R. Locko, H. Nurse, J. Cheng, G. Darkwa, V. Dowdy, B. Nicholas; Howard University: O. Randall (Principal Investigator), G. Ali, T. Retta, S. Xu (Study Coordinator), T. Alexander, M. Ketete, E. Mathew, D. Ordor, C. Tilghman; Johns Hopkins University: L. Appel (Principal Investigator), J. Charleston (Study Coordinator), C. Diggs, C. Harris, P. Miller, T. Shields, M.

Sotomayer; Martin Luther King, Sr.-Charles R. Drew Medical Center: K. Norris (Principal Investigator), H. Ward, D. Martins, M. Miller (Study Coordinator), H. Howell; Medical University of South Carolina: D. Cheek (Principal Investigator), C. Gadegbeku, D. Ploth, D. Brooks (Study Coordinator), N. Monestime, S. Murner, S. Thompson; 
Meharry Medical College: M. Faulkner (Principal Investigator), O. Adeyele, K. Phillips (Study Coordinator), G. Sanford, C. Weaver; Morehouse School of Medicine: W. Cleveland (Principal Investigator), A. Howard, K. Chapman, S. Plater, W. Smith (Study Coordinator); Mount Sinai School of Medicine: R. Phillips (Principal Investigator), M. Lipkowitz, A. Gabriel (Study Coordinator), A. Travis, J. Williams; Ohio State University: L. Hebert (Principal Investigator), M. Falkenhain, S. Ladson-Wofford, N. Nahman, K. Osei, L. Hiremath (Study Coordinator), A. Dodley, J. Parks, D. Veley; Rush Presbyterian St. Luke's Medical Center: G. Bakris (Principal Investigator), J. Lash, L. Fondren (Study Coordinator), L. Bagnuolo (Study Coordinator), J. Cohen (Study Coordinator), M. Powell (Study Coordinator), A. Smith, D. White, G. Henry, A. Johnson, T. Collins, S. Koshy, E. Afante; University of Alabama, Birmingham: S. Rostand (Principal Investigator), D. Thornley-Brown, R. Gay, C. Johnson (Study Coordinator), B. Key; University of California, San Diego: D. O'Connor (Principal Investigator), F. Gabbai, R. Parmer, F. Rao, J. Little, T. Makrogiannis, J. Mount (Study Coordinator), A. Ogundipe, A. Stephenson; University of Florida: C. Tisher (Principal Investigator), D. Allen, L. Burgin (Study Coordinator), A. Diaz, C. Sarmiento; University of Miami: J. Bourgoignie (Principal Investigator), G. Contreras, D. Florence-Green, A. Doss (Study Coordinator), J. Junco, D. Merrill, J. Vassallo, A. de Velasco; University of Michigan: K. Jamerson (Principal Investigator), F. Port, M. Keshishian, A. Ojo, S. Steigerwalt, D. Cornish-Zirker (Study Coordinator), T. Graham, A. Johnson, J. Layne, S. Nesbitt, K. Manchester, W. Bloembergen; University of Southern California: S. Massry (Principal Investigator), V. Campese, M. Smogorzewski, A. Richardson (Study Coordinator); University of Texas Southwestern Medical Center, Dallas: J. Middleton (Principal Investigator), E. Kuo, S. Leach, R. Toto, K. Jones, K. Hart, T. Lightfoot (Study Coordinator), L. Littmon, B. McNeill, C. Ying; Vanderbilt University: J. Lewis (Principal Investigator), G. Schulman, S. McLeroy, N. Rogers (Study Coordinator), M. Sika; National Institute of Diabetes and Digestive and Kidney Diseases: L.Y. Agodoa, J.P. Briggs, J.W. Kusek; Steering Committee Chair: J. Douglas; Data Coordinating Center (Cleveland Clinic Foundation): J. Gassman, G. Beck, V. Dennis, T. Greene, M. Kutner, K. Brittain (Study Coordinator), S. Sherer, R. Stewart, L. Tuason, S.-R. Wang, W. Zhang; Central Biochemistry Laboratory: F. Van Lente, J. Waletzky, C. O'Laughlin, C. Peck; Central GFR Laboratory: P. Hall, D. Pexa, H. Rolin; Blood Pressure Consultant: R. Byington; Psychologic Consultant: P. Greene; Data Safety and Monitoring Committee: R. Luke, V. Chinchilli, C. Cook, B. Falkner, C. Ford, R. Glassock, T. Karrison, T. Kotchen, E. Saunders, M. Secundy, D. Wesson.

We gratefully acknowledge support from the Office of Research in Minority Health and the donation of drug and some financial support to the National Institute of Diabetes and Digestive and Kidney Disease by Pfizer, AstraZeneca Pharmaceuticals, and King Pharmaceuticals. A special acknowledgment is extended to the AASK participants for their time and commitment to the trial.

The following authors have received honoraria from one or more pharmaceutical companies that manufacture antihypertensive medications: Lea, Lewis, Norris, Phillips, Rostand. The following authors have received funding for research from one or more pharmaceutical companies that manufacture antihypertensive medications: Appel, Greene, Norris, Phillips, Rostand. The following authors have served on the advisory panel for one or more pharmaceutical companies that manufacture antihypertensive medications: Norris. The following authors have stock in one or more pharmaceutical companies that manufacture antihypertensive medications: Rostand.

\section{References}

1. Stamler J, Vaccaro O, Neaton JD, Wentworth D. Diabetes, other risk factors, and 12-yr cardiovascular mortality for men screened in the Multiple Risk Factor Intervention Trial. Diabetes Care. 1993; 16:434-444. [PubMed: 8432214]

2. Mann JF, Gerstein HC, Pogue J, Bosch J, Yusuf S. Renal insufficiency as a predictor of cardiovascular outcomes and the impact of ramipril: The HOPE randomized trial. Ann Intern Med. 2001; 134:629-636. [PubMed: 11304102]

3. Muntner P, He J, Hamm L, Loria C, Whelton PK. Renal insufficiency and subsequent death resulting from cardiovascular disease in the United States. J Am Soc Nephrol. 2002; 13:745-753. [PubMed: 11856780]

4. Go AS, Chertow GM, Fan D, McCulloch CE, Hsu CY. Chronic kidney disease and the risks of death, cardiovascular events, and hospitalization. N Engl J Med. 2004; 351:1296-1305. [PubMed: 15385656]

5. US Renal Data System. USRDS 2003 Annual Data Report: Atlas of End-Stage Renal Disease in the United States, Bethesda, National Institutes of Health, National Institute of Diabetes and Digestive and Kidney Diseases. 2003

6. Coresh J, Astor BC, Greene T, Eknoyan G, Levey AS. Prevalence of chronic kidney disease and decreased kidney function in the adult US population: Third National Health and Nutrition Examination Survey. Am J Kidney Dis. 2003; 41:1-12. [PubMed: 12500213] 
7. Perneger TV, Klag MJ, Feldman HI, Whelton PK. Projections of hypertension-related renal disease in middle-aged residents of the United States. JAMA. 1993; 269:1272-1277. [PubMed: 8437305]

8. Lea J, Greene T, Hebert L, Lipkowitz M, Massry S, Middleton J, Rostand SG, Miller E, Smith W, Bakris GL. The relationship between magnitude of proteinuria reduction and risk of end-stage renal disease: Results of the African American study of kidney disease and hypertension. Arch Intern Med. 2005; 165:947-953. [PubMed: 15851648]

9. Klag MJ, Whelton PK, Randall BL, Neaton JD, Brancati FL, Stamler J. End-stage renal disease in African-American and white men. 16-year MRFIT findings. JAMA. 1997; 277:1293-1298. [PubMed: 9109467]

10. Powe NR. To have and have not: Health and health care disparities in chronic kidney disease. Kidney Int. 2003; 64:763-772. [PubMed: 12846781]

11. Norris KC, Agodoa LY. Unraveling the racial disparities associated with kidney disease. Kidney Int. 2005; 68:914-924. [PubMed: 16105022]

12. Post WS, Hill MN, Dennison CR, Weiss JL, Gerstenblith G, Blumenthal RS. High prevalence of target organ damage in young, African American inner-city men with hypertension. J Clin Hypertens (Greenwich). 2003; 5:24-30. [PubMed: 12556650]

13. Wright JT Jr, Kusek JW, Toto RD, Lee JY, Agodoa LY, Kirk KA, Randall OS, Glassock R. Design and baseline characteristics of participants in the African American Study of Kidney Disease and Hypertension (AASK) Pilot Study. Control Clin Trials. 1996; 17(Suppl 4):3S-16S. [PubMed: 8889350]

14. Agodoa LY, Appel L, Bakris GL, Beck G, Bourgoignie J, Briggs JP, Charleston J, Cheek D, Cleveland W, Douglas JG, Douglas M, Dowie D, Faulkner M, Gabriel A, Gassman J, Greene T, Hall Y, Hebert L, Hiremath L, Jamerson K, Johnson CJ, Kopple J, Kusek J, Lash J, Lea J, Lewis JB, Lipkowitz M, Massry S, Middleton J, Miller ER 3rd, Norris K, O’Connor D, Ojo A, Phillips RA, Pogue V, Rahman M, Randall OS, Rostand S, Schulman G, Smith W, Thornley-Brown D, Tisher CC, Toto RD, Wright JT Jr, Xu S. Effect of ramipril vs amlodipine on renal outcomes in hypertensive nephrosclerosis: A randomized controlled trial. JAMA. 2001; 285:2719-2728. [PubMed: 11386927]

15. Wright JT Jr, Bakris G, Greene T, Agodoa LY, Appel LJ, Charleston J, Cheek D, DouglasBaltimore JG, Gassman J, Glassock R, Hebert L, Jamerson K, Lewis J, Phillips RA, Toto RD, Middleton JP, Rostand SG. Effect of blood pressure lowering and antihypertensive drug class on progression of hypertensive kidney disease: Results from the AASK trial. JAMA. 2002; 288:2421-2431. [PubMed: 12435255]

16. Perloff D, Grim C, Flack J, Frohlich ED, Hill M, McDonald M, Morgenstern BZ. Human blood pressure determination by sphygmomanometry. Circulation. 1993; 88:2460-2470. [PubMed: 8222141]

17. Keane WF, Brenner BM, de Zeeuw D, Grunfeld JP, McGill J, Mitch WE, Ribeiro AB, Shahinfar S, Simpson RL, Snapinn SM, Toto R. The risk of developing end-stage renal disease in patients with type 2 diabetes and nephropathy: The RENAAL study. Kidney Int. 2003; 63:1499-1507. [PubMed: 12631367]

18. Ruggenenti P, Perna A, Mosconi L, Pisoni R, Remuzzi G. Urinary protein excretion rate is the best independent predictor of ESRF in non-diabetic proteinuric chronic nephropathies. "Gruppo Italiano di Studi Epidemiologici in Nefrologia” (GISEN). Kidney Int. 1998; 53:1209-1216. [PubMed: 9573535]

19. Hunsicker LG, Adler S, Caggiula A, England BK, Greene T, Kusek JW, Rogers NL, Teschan PE. Predictors of the progression of renal disease in the Modification of Diet in Renal Disease Study. Kidney Int. 1997; 51:1908-1919. [PubMed: 9186882]

20. Bohle A, Wehrmann M, Greschniok A, Junghans R. Renal morphology in essential hypertension: Analysis of 1177 unselected cases. Kidney Int Suppl. 1998; 67:S205-S206. [PubMed: 9736291]

21. Levin A. Clinical epidemiology of cardiovascular disease in chronic kidney disease prior to dialysis. Semin Dial. 2003; 16:101-105. [PubMed: 12641872]

22. Levin A, Singer J, Thompson CR, Ross H, Lewis M. Prevalent left ventricular hypertrophy in the predialysis population: Identifying opportunities for intervention. Am J Kidney Dis. 1996; 27:347354. [PubMed: 8604703] 
23. Suzuki K, Kato K, Hanyu O, Nakagawa O, Aizawa Y. Left ventricular mass index increases in proportion to the progression of diabetic nephropathy in type 2 diabetic patients. Diabetes Res Clin Pract. 2001; 54:173-180. [PubMed: 11689272]

24. Kalantar-Zadeh K, Block G, Humphreys MH, Kopple JD. Reverse epidemiology of cardiovascular risk factors in maintenance dialysis patients. Kidney Int. 2003; 63:793-808. [PubMed: 12631061]

25. Wright JT Jr, Agodoa L, Contreras G, Greene T, Douglas JG, Lash J, Randall O, Rogers N, Smith MC, Massry S. Successful blood pressure control in the African American Study of Kidney Disease and Hypertension. Arch Intern Med. 2002; 162:1636-1643. [PubMed: 12123409]

26. Haroun MK, Jaar BG, Hoffman SC, Comstock GW, Klag MJ, Coresh J. Risk factors for chronic kidney disease: A prospective study of 23,534 men and women in Washington County, Maryland. J Am Soc Nephrol. 2003; 14:2934-2941. [PubMed: 14569104]

27. Pinto-Sietsma SJ, Mulder J, Janssen WM, Hillege HL, de Zeeuw D, de Jong PE. Smoking is related to albuminuria and abnormal renal function in nondiabetic persons. Ann Intern Med. 2000; 133:585-591. [PubMed: 11033585]

28. Chuahirun T, Khanna A, Kimball K, Wesson DE. Cigarette smoking and increased urine albumin excretion are interrelated predictors of nephropathy progression in type 2 diabetes. Am J Kidney Dis. 2003; 41:13-21. [PubMed: 12500217]

29. Regalado M, Yang S, Wesson DE. Cigarette smoking is associated with augmented progression of renal insufficiency in severe essential hypertension. Am J Kidney Dis. 2000; 35:687-694. [PubMed: 10739791]

30. Keith DS, Nichols GA, Gullion CM, Brown JB, Smith DH. Longitudinal follow-up and outcomes among a population with chronic kidney disease in a large managed care organization. Arch Intern Med. 2004; 164:659-663. [PubMed: 15037495]

31. Miskulin DC, Meyer KB, Martin AA, Fink NE, Coresh J, Powe NR, Klag MJ, Levey AS. Comorbidity and its change predict survival in incident dialysis patients. Choices for Healthy Outcomes in Caring for End-Stage Renal Disease (CHOICE) Study. Am J Kidney Dis. 2003; 41:149-161. [PubMed: 12500232]

32. Collins AJ. Anaemia management prior to dialysis: Cardiovascular and cost-benefit observations. Nephrol Dial Transplant. 2003; 18(Suppl 2):ii2-ii6. [PubMed: 12819293]

33. Keane WF, Collins AJ. Influence of co-morbidity on mortality and morbidity in patients treated with hemodialysis. Am J Kidney Dis. 1994; 24:1010-1018. [PubMed: 7985662]

34. Fine LG, Bandyopadhay D, Norman JT. Is there a common mechanism for the progression of different types of renal diseases other than proteinuria? Towards the unifying theme of chronic hypoxia. Kidney Int Suppl. 2000; 75:S22-S26. [PubMed: 10828757]

35. Silverberg DS, Wexler D, Blum M, Keren G, Sheps D, Leibovitch E, Brosh D, Laniado S, Schwartz D, Yachnin T, Shapira I, Gavish D, Baruch R, Koifman B, Kaplan C, Steinbruch S, Iaina A. The use of subcutaneous erythropoietin and intravenous iron for the treatment of the anemia of severe, resistant congestive heart failure improves cardiac and renal function and functional cardiac class, and markedly reduces hospitalizations. J Am Coll Cardiol. 2000; 35:1737-1744. [PubMed: 10841219]

36. Stam F, van Guldener C, Schalkwijk CG, ter Wee PM, Donker AJ, Stehouwer CD. Impaired renal function is associated with markers of endothelial dysfunction and increased inflammatory activity. Nephrol Dial Transplant. 2003; 18:892-898. [PubMed: 12686661]

37. Schalkwijk CG, Ter Wee PM, Stehouwer CD. Plasma levels of AGE peptides in type 1 diabetic patients are associated with serum creatinine and not with albumin excretion rate: Possible role of AGE peptide-associated endothelial dysfunction. Ann N Y Acad Sci. 2005; 1043:662-670. [PubMed: 16037290]

38. Modification of Diet in Renal Disease Study Group. Effects of diet and antihypertensive therapy on creatinine clearance and serum creatinine concentration in the Modification of Diet in Renal Disease Study. J Am Soc Nephrol. 1996; 7:556-566. published erratum appears in J Am Soc Nephrol 8: 1354, 1997. [PubMed: 8724889]

39. Block GA, Klassen PS, Lazarus JM, Ofsthun N, Lowrie EG, Chertow GM. Mineral metabolism, mortality, and morbidity in maintenance hemodialysis. J Am Soc Nephrol. 2004; 15:2208-2218. [PubMed: 15284307] 
40. Kestenbaum B, Sampson JN, Rudser KD, Patterson DJ, Seliger SL, Young B, Sherrard DJ, Andress DL. Serum phosphate levels and mortality risk among people with chronic kidney disease. J Am Soc Nephrol. 2005; 16:520-528. [PubMed: 15615819] 


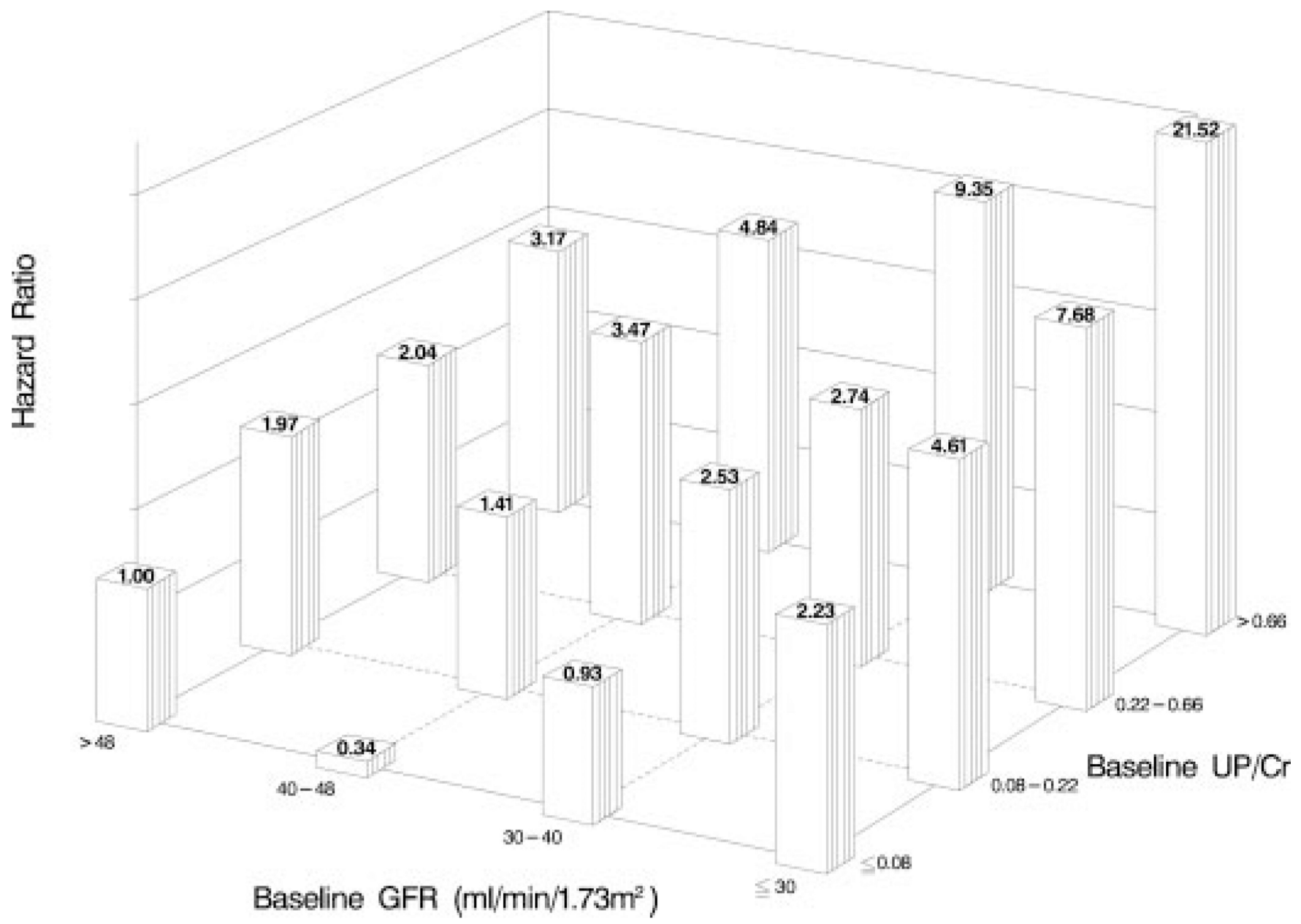

Figure 1.

Joint association of the renal composite (GFR event or ESRD) with baseline proteinuria and baseline GFR. Shown are hazard ratios of the renal composite (GFR event or ESRD) for the designated combinations of levels of baseline proteinuria (expressed as baseline urine protein/creatinine ratio) and baseline GFR, adjusting for age, gender, and randomized treatment groups. Both baseline factors are strongly predictive of the occurrence of a GFR event or ESRD after controlling for the other. 
GFR Event or ESRD

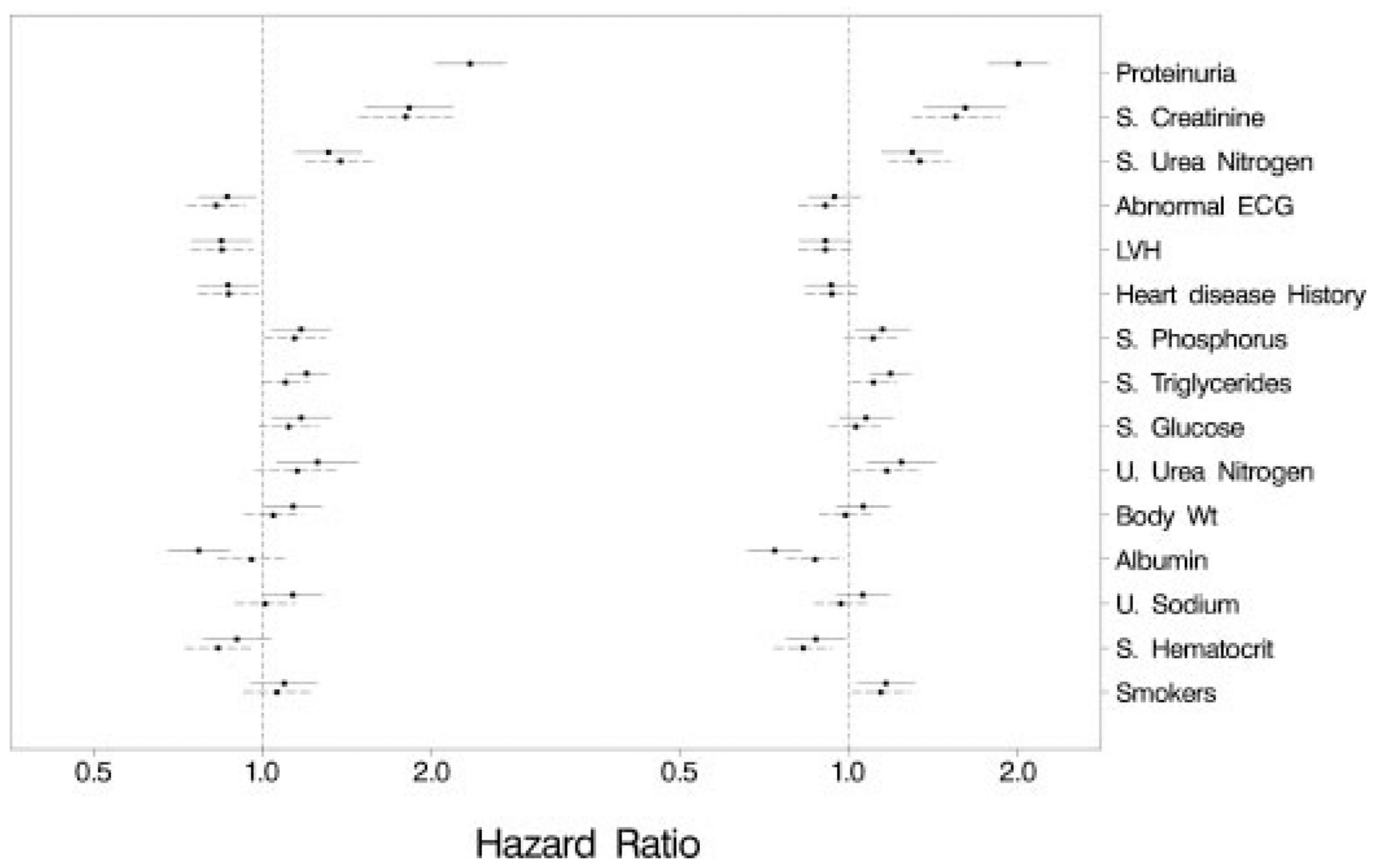

\section{Figure 2.}

Association of composite outcomes with baseline factors, with and without adjustment for baseline proteinuria. Shown are the hazard ratios (with 95\% confidence intervals [CI]) of two composite outcomes that are associated with 1-SD increases in the indicated baseline factors: (1) GFR event or ESRD and (2) GFR event, ESRD, or death. Results are provided both without adjustment for baseline proteinuria (CI indicated with solid lines) and then with adjustment for baseline proteinuria (CI indicated with dashed lines). All analyses are adjusted for age, gender, mean baseline GFR, and randomized treatment groups. S., serum; ECG, electrocardiogram; LVH, left ventricular hypertrophy; U., urine. 


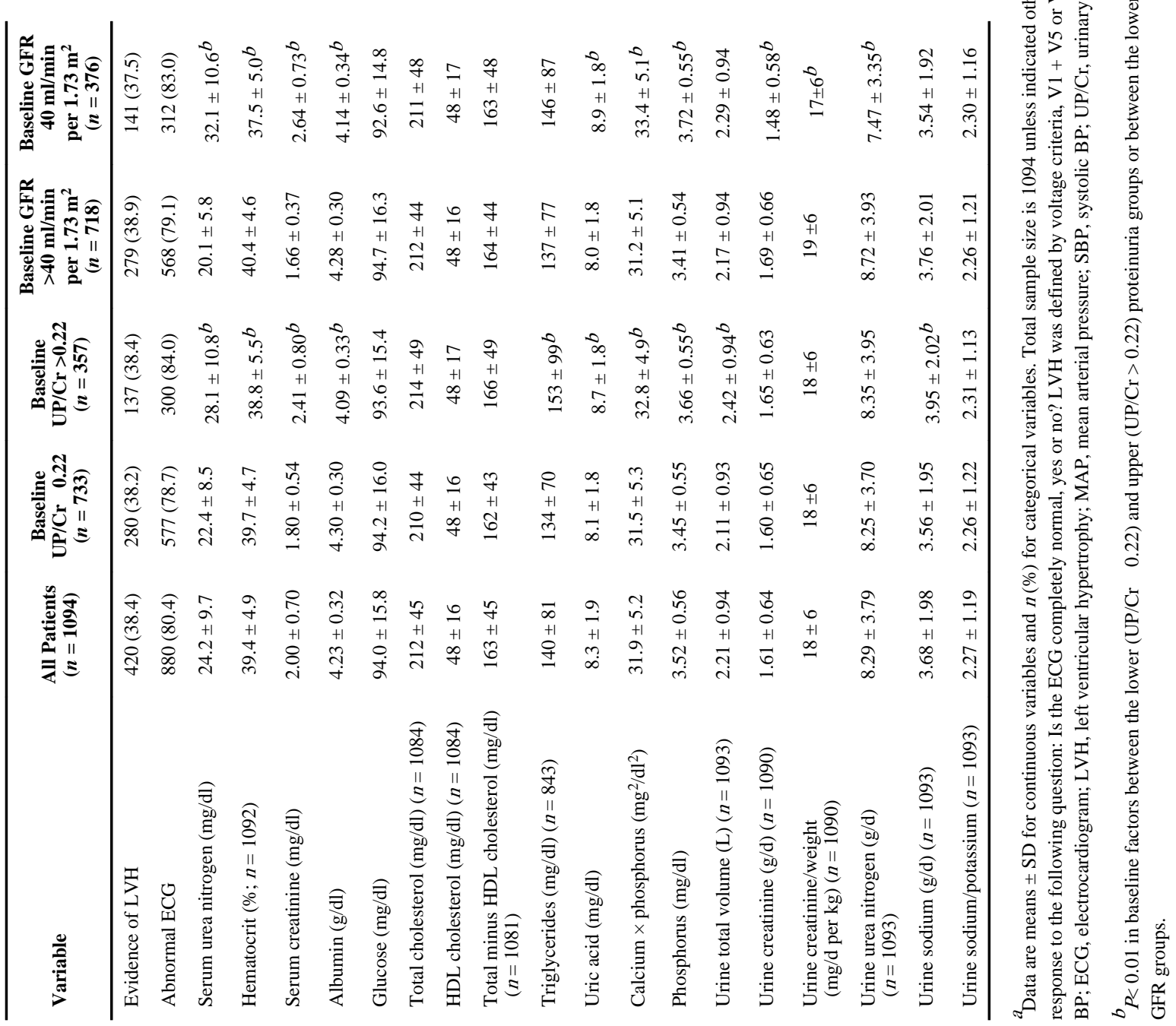


Table 2

Univariate relationships between four baseline factors and risk for GFR event or ESRD ${ }^{a}$

\begin{tabular}{lcc}
\hline Baseline Factors & HR $(\mathbf{9 5 \%}$ CI $)$ & $\boldsymbol{P}$ \\
\hline Female gender & $1.05(0.82$ to 1.34$)$ & 0.71 \\
Age (per 10-yr increase) & $0.74(0.67$ to 0.83$)$ & $<0.0001$ \\
UP/Cr (per doubling) & $1.59(1.50$ to 1.69$)$ & $<0.0001$ \\
GFR (per 10-ml/min per & $1.71(1.53$ to 1.90$)$ & $<0.0001$ \\
$1.73 \mathrm{~m}^{2}$ decrease when & & \\
GFR $\leq 40)$ & & \\
GFR (per 10 -ml/min per & $1.07(0.97$ to 1.17$)$ & 0.16 \\
$1.73 \mathrm{~m}^{2}$ decrease when & & \\
GFR $>40)$ & & \\
\hline
\end{tabular}

${ }^{a}$ Shown are the hazard ratios (HR) of the GFR event or ESRD composite outcome associated with female gender, with the designated increases in age, baseline proteinuria, and a reduced baseline GFR. Each baseline factor is considered individually, without controlling for the other factors. CI, confidence interval 
Table 3

Association of risk for GFR event or ESRD with baseline factors ${ }^{a}$

\begin{tabular}{|c|c|c|c|c|}
\hline \multirow[t]{2}{*}{ Baseline Factors } & \multicolumn{2}{|c|}{$\begin{array}{l}\text { Adjusting for Randomized } \\
\text { Group, Baseline GFR, Age, } \\
\text { and Gender }\end{array}$} & \multicolumn{2}{|c|}{$\begin{array}{l}\text { Adjusting for Randomized } \\
\text { Group, Baseline GFR, Age, } \\
\text { Gender, and UP/Cr }\end{array}$} \\
\hline & HR $(95 \%$ CI $)$ & $P$ & HR $(95 \%$ CI $)$ & $P$ \\
\hline $\mathrm{UP} / \mathrm{Cr}$ (doubling) $b$ & 1.47 (1.38 to 1.58$)$ & $<0.0001$ & & \\
\hline Serum creatinine $(0.5 \mathrm{mg} / \mathrm{dl})^{b}$ & 1.54 (1.35 to 1.75$)$ & $<0.0001$ & $1.52(1.33$ to 1.75$)$ & $<0.0001$ \\
\hline Serum urea nitrogen $(5 \mathrm{mg} / \mathrm{dl})^{b}$ & 1.15 (1.07 to 1.24$)$ & 0.0001 & 1.18 (1.10 to 1.27$)$ & $<0.0001$ \\
\hline ECG abnormal versus normal $b$ & $0.70(0.52$ to 0.94$)$ & 0.02 & $0.62(0.46$ to 0.84$)$ & 0.002 \\
\hline $\mathrm{LVH}$ versus no $\mathrm{LVH}^{b}$ & $0.71(0.55$ to 0.92$)$ & 0.009 & $0.71(0.55$ to 0.92$)$ & 0.01 \\
\hline Heart disease history versus no $b$ & $0.75(0.59$ to 0.97$)$ & 0.03 & $0.76(0.59$ to 0.97$)$ & 0.03 \\
\hline Phosphorus $(0.3 \mathrm{mg} / \mathrm{dl})^{b}$ & 1.09 (1.02 to 1.16$)$ & 0.01 & 1.07 (1.00 to 1.15$)$ & 0.05 \\
\hline Triglycerides $(50 \mathrm{mg} / \mathrm{dl})^{c}$ & $1.12(1.06$ to 1.18$)$ & $<0.0001$ & $1.06(1.00$ to 1.13$)$ & 0.06 \\
\hline Glucose $(10 \mathrm{mg} / \mathrm{dl})^{c}$ & $1.11(1.02$ to 1.20$)$ & 0.01 & 1.07 (0.99 to 1.16$)$ & 0.09 \\
\hline Urine urea nitrogen $\leq 7.8(2 \mathrm{~g} / \mathrm{d})$ & $0.90(0.77$ to 1.06$)$ & 0.20 & $0.90(0.77$ to 1.06$)$ & 0.21 \\
\hline Urine urea nitrogen $>7.8(2 \mathrm{~g} / \mathrm{d})^{\mathcal{c}}$ & 1.13 (1.03 to 1.23$)$ & 0.008 & $1.08(0.98$ to 1.18$)$ & 0.11 \\
\hline Body weight $(5 \mathrm{~kg})^{c}$ & 1.03 (1.00 to 1.06$)$ & 0.04 & $1.01(0.98$ to 1.04$)$ & 0.46 \\
\hline $\operatorname{Albumin}(0.2 \mathrm{~g} / \mathrm{dl})^{\mathcal{C}}$ & 0.85 (0.79 to 0.92$)$ & $<0.0001$ & 0.97 (0.89 to 1.06$)$ & 0.52 \\
\hline Urine sodium $(1 \mathrm{~g} / \mathrm{d})^{\mathcal{c}}$ & 1.07 (1.00 to 1.13 ) & 0.04 & $1.01(0.94$ to 1.07$)$ & 0.87 \\
\hline Hematocrit $(2 \%)^{d}$ & $0.96(0.91$ to 1.01$)$ & 0.14 & 0.93 (0.88 to 0.98$)$ & 0.01 \\
\hline Current versus never smokers & $1.20(0.91$ to 1.59$)$ & 0.20 & $1.13(0.85$ to 1.50$)$ & 0.40 \\
\hline Past versus never smokers & $0.94(0.69$ to 1.30$)$ & 0.72 & $0.94(0.68$ to 1.29$)$ & 0.70 \\
\hline Height $(5 \mathrm{~cm})$ & $1.05(0.97$ to 1.14$)$ & 0.26 & 1.09 (1.00 to 1.18$)$ & 0.05 \\
\hline Total minus HDL cholesterol ( $20 \mathrm{mg} / \mathrm{dl})$ & $1.03(0.97$ to 1.09$)$ & 0.35 & $0.95(0.90$ to 1.00$)$ & 0.07 \\
\hline MAP (10 mmHg) & $1.00(0.94$ to 1.07$)$ & 0.95 & 0.94 (0.87 to 1.01$)$ & 0.08 \\
\hline $\mathrm{SBP}(10 \mathrm{mmHg})$ & $1.01(0.96$ to 1.06$)$ & 0.64 & $0.96(0.91$ to 1.01$)$ & 0.09 \\
\hline DBP $(10 \mathrm{mmHg})$ & $0.99(0.92$ to 1.07$)$ & 0.79 & 0.94 (0.86 to 1.02$)$ & 0.11 \\
\hline Calcium $\times$ phosphorus $\left(2 \mathrm{mg}^{2} / \mathrm{dl}^{2}\right)$ & 1.04 (0.99 to 1.09 ) & 0.15 & 1.04 (0.99 to 1.09$)$ & 0.15 \\
\hline Total cholesterol ( $20 \mathrm{mg} / \mathrm{dl})$ & $1.04(0.99$ to 1.10$)$ & 0.14 & $0.96(0.91$ to 1.01$)$ & 0.15 \\
\hline Familial diagnosis of ESRD & $0.78(0.54$ to 1.14$)$ & 0.20 & $0.76(0.52$ to 1.11$)$ & 0.16 \\
\hline Urine sodium/potassium ( 0.5 unit) & $1.03(0.98$ to 1.09$)$ & 0.18 & $1.03(0.98$ to 1.09$)$ & 0.22 \\
\hline SBP-DBP (10 mmHg) & $1.04(0.96$ to 1.11$)$ & 0.34 & $0.96(0.89$ to 1.03$)$ & 0.27 \\
\hline HDL cholesterol (5 mg/dl) & $1.03(0.99$ to 1.07$)$ & 0.16 & $1.02(0.98$ to 1.06$)$ & 0.41 \\
\hline Uric acid $(1 \mathrm{mg} / \mathrm{dl})$ & $1.02(0.95$ to 1.09$)$ & 0.64 & $1.03(0.96$ to 1.10$)$ & 0.44 \\
\hline Parental diagnosis of hypertension & $0.91(0.69$ to 1.18$)$ & 0.47 & $0.92(0.70$ to 1.19$)$ & 0.51 \\
\hline Urine creatinine/weight $(0.003 \mathrm{~g} / \mathrm{d}$ per $\mathrm{kg})$ & $0.98(0.91$ to 1.05$)$ & 0.51 & 0.98 (0.91 to 1.06$)$ & 0.62 \\
\hline Years with hypertension (1 yr) & $1.00(0.99$ to 1.01$)$ & 0.82 & $1.00(0.98$ to 1.01$)$ & 0.63 \\
\hline Urine creatinine $(0.3 \mathrm{~g} / \mathrm{d})$ & $1.05(0.98$ to 1.13$)$ & 0.19 & $1.02(0.94$ to 1.09$)$ & 0.68 \\
\hline Urine total volume $(0.5 \mathrm{~L})$ & $1.06(1.00$ to 1.13$)$ & 0.06 & $0.99(0.92$ to 1.06$)$ & 0.74 \\
\hline
\end{tabular}




\begin{tabular}{lccccc}
\hline Baseline Factors & $\begin{array}{c}\text { Adjusting for Randomized } \\
\text { Group, Baseline GFR, Age, } \\
\text { and Gender }\end{array}$ & $\begin{array}{c}\text { Adjusting for Randomized } \\
\text { Group, Baseline GFR, Age, } \\
\text { Gender, and UP/Cr }\end{array}$ \\
\cline { 2 - 6 } & HR $(\mathbf{9 5 \%}$ CI) & $\boldsymbol{P}$ & HR (95\% CI) & $\boldsymbol{P}$ \\
\hline Income $\$ 0$ to $\$ 14,999$ versus mid-high & $0.97(0.74$ to 1.29$)$ & 0.85 & $0.98(0.74$ to 1.29$)$ & 0.88 \\
Income decline versus mid-high & $1.00(0.70$ to 1.41$)$ & 0.98 & $0.97(0.68$ to 1.37$)$ & 0.84 \\
No high school degree versus degree & $0.90(0.69$ to 1.19$)$ & 0.46 & $0.98(0.75$ to 1.29$)$ & 0.90 \\
BMI $\left(2 \mathrm{~kg} / \mathrm{m}^{2}\right)$ & $1.03(1.00$ to 1.07$)$ & 0.08 & $1.00(0.97$ to 1.04$)$ & 0.93 \\
\hline
\end{tabular}

${ }^{a}$ For continuous variables, the HR indicate the proportional change in risk associated with each increase in the baseline factor by the amount indicated in parentheses. For categorical variables, the HR indicate the proportional change in risk for the presence of the indicated factor versus absence of the factor. Abnormal ECG findings were defined in response to the following question: Is the EKG completely normal, yes or no? $\mathrm{LVH}$ was defined by voltage criteria, V1 + V5 or V6 $>35 \mathrm{~mm}$, or V5 or V6>25 mm.

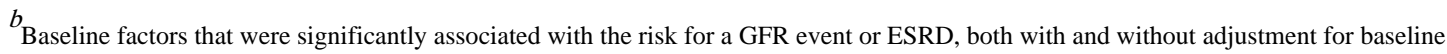
proteinuria in addition to age, gender, and baseline GFR.

${ }^{c}$ Baseline factors that were significantly associated with the risk for a GFR event or ESRD, without but not with adjustment for baseline proteinuria in addition to age, gender, and baseline GFR.

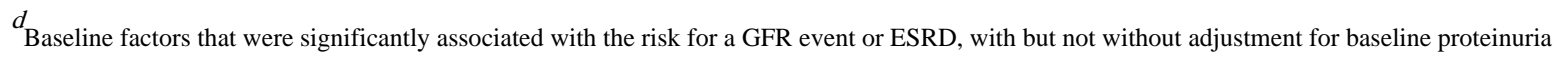
in addition to age, gender, and baseline GFR. 